\title{
Receptive (aural) vocabulary development in children with permanent bilateral sensorineural hearing impairment
}

\author{
C KIESE-HimmeL
}

\begin{abstract}
Objective: The receptive (aural) vocabulary development of children with binaural-aided residual hearing was investigated in a prospective longitudinal analysis (repeated measures).

Patient and methods: Thirty-three children with sensorineural hearing loss, without major co-morbidities (mean age at the first testing point, 56.2 months, standard deviation 19.0 months) were recruited from the 1994 German Goettinger Hearing Language Register. Their receptive vocabulary was measured using standardised tests (with reference to normal hearing child performance) on three separate test points (mean follow up, 18.7 months, standard deviation 5.0 months).

Results: On average, the study group scored below the normal range at the first and second tests and made a significant improvement at the last test. The degree of hearing loss was found to be significantly correlated to vocabulary performance at all time points, with increasing correlation coefficients. At the third test, significant predictive variables for successful receptive vocabulary outcome were found to be: degree of hearing loss $(t=5.43 ; p<0.0001)$; age at diagnosis $(t=2.29 ; p=0.03)$; and nonverbal intelligence $(t=2.82 ; p=0.009)$.

Conclusion: If permanent childhood hearing impairment is mild and/or is detected early, and if the child grows up in a monolingual environment, the development of receptive vocabulary within the normal range is possible.
\end{abstract}

Key words: Child; Hearing Loss, Sensorineural; Language; Vocabulary; Hearing Aids

\section{Introduction}

Language input plays an eminent role in formation of the developing language system in infants. Infants naturally acquire their native vocabulary from speech heard in their home environment, from which they form phonological representations. There is also substantial evidence for the role of phonological memory in vocabulary development for the sound structures of words. Receptive (aural) vocabulary development is a very important facet of oral language acquisition and generally precedes expressive vocabulary. ${ }^{1}$ Vocabulary knowledge is important for understanding the world and for language competence. $^{2}$ Lexical comprehension begins at approximately nine months and typically increases with age. The child's receptive lexicon exceeds its expressive vocabulary by a certain amount at different ages. "Words are the building blocks of language'; ${ }^{3}$ therefore, vocabulary size and syntactic development are related. The emergence as well as the elaboration of grammar is highly dependent upon vocabulary size. ${ }^{1,4-6}$ Children who can hear and comprehend a large number of words are much more likely to develop an oral linguistic system. In contrast, children with delayed acquisition of receptive vocabulary are at risk of delayed expressive vocabulary development, which in turn significantly delays the acquisition of spoken language skills and, ultimately, compromises academic achievement. ${ }^{7,8}$

The development of spoken language is one of the most relevant outcomes of clinical interventions designed to habilitate hearing in young children with hearing loss. Early amplification promotes receptive language development, because it improves the acoustic sensory information required to perceive and understand spoken words. Recent research has demonstrated that children with permanent sensorineural hearing loss, without other disabilities, have problems achieving an age-appropriate vocabulary. ${ }^{9-13}$ Such children are, in general, delayed in their level of vocabulary knowledge, compared with hearing children, and tend to have smaller lexicons. Mayne et al. ${ }^{11}$ concluded from their study results that '... it appears that the receptive vocabulary development of deaf and hard-of-hearing children 
from eight to 22 months is considerably delayed compared with reports of children with normal hearing peers'. Moeller et al. ${ }^{9}$ examined the receptive vocabulary of 150 hearing-impaired or deaf children from the ages of 4.5 to 20 years. On average, these children showed severe delays compared with hearing children of the same age. Moeller et al. found that the difference between receptive vocabulary age and chronological age was greatest in the oldest age groups, with a plateau in development at 12 to 13 years.

Very little information is available on the receptive vocabulary outcome of hearing-impaired preschool and school-age children with mild to profound hearing loss who use personal hearing aids. Most of the literature on language growth outcomes relates to children with severe to profound hearing losses who receive cochlear implants. ${ }^{14-22}$ It is impossible to investigate the oral language development of a large group of congenitally hearing-impaired children in Germany, because of the absence of compulsory universal newborn hearing screening. Therefore, the present study was based on an analysis of longitudinal data from hearing-impaired and hearing-aided children in a defined geographical catchment area of Lower Saxony, Germany (identified from the Goettinger Hearing Language Register). This area contains about 1 million of inhabitants and covers patients living in rural and urban regions within a $100 \mathrm{~km}$ radius of the city of Goettingen Hearing Language Register. The data reported here were routinely collected in the Goettinger. More information on the Goettinger Hearing Language Register of Goettingen is shown in Appendix 1.

The main objectives of this study were (1) to assess receptive vocabulary size in children who had not undergone newborn hearing screening or cochlear implantation, who were hearing-impaired and using hearing aids, (2) to establish an evidence base for receptive vocabulary development over time, especially in order to explore the relationship between receptive vocabulary and degree of hearing loss and age of diagnosis, and (3) to predict the likely receptive vocabulary outcome for the hearing-impaired subjects.

\section{Materials and methods \\ Participants}

All children who met the following criteria were included in the study: permanent, bilateral sensorineural hearing loss $>20 \mathrm{~dB}$ in the better hearing ear, across four frequencies $(0.5,1,2$ and $4 \mathrm{kHz})$; no other significant handicapping conditions or major co-morbidities; no intellectual disability; no history of persistent and/or chronic middle-ear infections; current use of personal amplification (i.e. hearing aids); and completed data for the study's three lexical measurements.

Thirty-three children (14 boys and 19 girls) met the inclusion criteria. Of these children, 10 had 'mild' hearing loss (i.e. $>20-40 \mathrm{~dB} \mathrm{HL}$ ); 17 had 'moderate' hearing loss (i.e. $41-70 \mathrm{~dB} \mathrm{HL}$ ); four had 'severe' hearing loss (i.e. 71-90 dB HL); and two had 'profound respectively residual hearing loss' (i.e. $>90 \mathrm{~dB}$ HL). The aetiology of hearing loss was unknown in 25 children (76 per cent) (i.e. there was no apparent medical or genetic history that could explain the hearing loss), believed to be congenital in seven children (21 per cent), and postnatal infection (scarlatina) in one child (3 per cent). The overall average age at diagnosis was 53.0 months (standard deviation (SD) 18.3 months; median 54 months). Table I shows the mean ages at diagnosis for the subgroups of the study group. The children were first fitted with binaural personal amplification (i.e. conventional hearing aids) at a mean age of 53.3 (SD 18.3) months, and regularly used them. Their preferred communication mode was oral-aural, in German in 23 cases. Ten children grew up bilingually-biculturally (three were Turkish; two Russian; two had deaf parents signing German; and one each were French, Albanian and Arabian). Seven of these children were born in Germany, so they had to acquire two lexical systems simultaneously.

TABLE I

SUBJECTS' AGES AT HEARING LOSS DIAGNOSIS, IN MONTHS

\begin{tabular}{|c|c|c|c|c|c|c|c|}
\hline Subgroup & $n$ & Mean & $\mathrm{SD}$ & Median & Min & Max & Range \\
\hline \multicolumn{8}{|l|}{ Hearing loss degree } \\
\hline Mild $(>20-40 \mathrm{~dB}$ HL $)$ & 10 & 53.3 & 17.1 & 53.5 & 24 & 77 & 53 \\
\hline Moderate (41-70 dB HL) & 17 & 54.9 & 17.1 & 62 & 22 & 77 & 55 \\
\hline Severe (71-90 dB HL) & 4 & 43.5 & 22.0 & 36.5 & 26 & 75 & 49 \\
\hline Profound ( $>90 \mathrm{~dB} \mathrm{HL})$ & 2 & 54.5 & 38.9 & 54.5 & 27 & 82 & 55 \\
\hline \multicolumn{8}{|l|}{ Oral communication mode } \\
\hline Monolingual German & 23 & $48.8^{*}$ & 17.0 & 52 & 22 & 74 & 52 \\
\hline Bilingual & 10 & $62.6^{*}$ & 18.3 & 71 & 28 & 82 & 54 \\
\hline \multicolumn{8}{|l|}{ Hearing loss onset } \\
\hline Congenital & 7 & 36.9 & 9.7 & 37 & 26 & 54 & 28 \\
\hline Postnatal & 1 & 28.0 & - & - & - & - & - \\
\hline Unknown & 25 & 58.2 & 17.0 & 64 & 22 & 82 & 60 \\
\hline All & 33 & 53.0 & 18.3 & 54 & 22 & 82 & 60 \\
\hline
\end{tabular}

${ }^{*} p=0.027 . \mathrm{SD}=$ standard deviation $; \min =$ minimum $; \max =$ maximum 
The Goettinger Hearing Language Register children received no therapy for oral language acquisition if their standardised vocabulary score at the first study test was age-appropriate or better.

Six children in the study group remained without any therapy for the whole follow-up time. Therapeutic intervention for the remaining children varied at different ages; they underwent oral speech-language therapy (conducted by a speech-language therapist), and/or enrolment in an early home intervention programme. This programme offered weekly intervention by a specialist hard-of-hearing children's teacher, who instructed parents about appropriate communication (e.g. arranging appropriate input in a setting that would encourage the child's verbal response (Table II).

\section{Audiological assessment}

Each child's hearing status assessment consisted of: a clinical history, including information on familial hearing loss and on the child's prenatal, birth and perinatal data; an otoscopic examination; and tympanometry (to rule out a conductive component due to middle-ear pathology). Hearing sensitivity was assessed using puretone audiometry with headphones (air and bone conduction thresholds; average for $0.5,1,2$ and $4 \mathrm{kHz}$ ). Auditory brainstem response testing was used below the age of 3.0 years or in children who were difficult to test.

\section{Measures of nonverbal intelligence}

Nonverbal cognitive ability was assessed at the first test point, using the Columbia Mental Maturity Scale, ${ }^{23}$ with age norms for German children from the age of 3.0 years. ${ }^{24}$ For children aged 4.9 years and over, the German version of Raven's Coloured Progressive Matrices was used. ${ }^{25}$

\section{Vocabulary assessment}

Children's receptive spoken German vocabulary (i.e. number of words understood at a given age) was measured at each of the three test points, using one of the following standardised, valid and reliable picture vocabulary tests (requiring selection of one picture from four choices), individually administered according to the test instruction manuals. The receptive vocabulary subtest of the Language Development Test For Two Years Old was used for children aged 24 to 35 months. ${ }^{26}$ The German translation of the Peabody Picture Vocabulary Test was used for

TABLE II

SUBJECTS' TREATMENT, AT THE THREE TEST POINTS

\begin{tabular}{lrrr}
\hline Treatment & $\mathrm{t} 1(n)$ & $\mathrm{t} 2(n)$ & $\mathrm{t} 3(n)$ \\
\hline None & 18 & 8 & 10 \\
Oral speech-language therapy & 5 & 9 & 21 \\
Early home intervention programme & 5 & 4 & 2 \\
Oral speech-language therapy + early & 4 & 12 & 0 \\
$\quad$ home intervention programme & 1 & - & - \\
Occupational therapy & 1 & - \\
\hline
\end{tabular}

$\mathrm{t}=\mathrm{test}$ children aged 36 to 47 or 97 to 120 months. $^{27}$ Finally, the picture vocabulary subtest of the French Pictorial Test of Intelligence was used for children aged 48 to 96 months. ${ }^{28}$

The tests are given by presenting the words in spoken German. The items of all tests were arranged in order of increasing difficulty. The overall test score was expressed in terms of standard scores, based on a representative sample of hearing children of a similar age (T-score: mean $=50 ; \mathrm{SD}=10)$. The T-score were used to interpret a child's performance for the purposes of data analysis. Higher scores indicated a larger vocabulary size.

The average interval between a child's diagnosis of hearing impairment and their first study test was 3.2 (SD 4.0) months. The mean interval between the first and last test was 18.7 (SD 5.1) months. On average, subjects were aged 56.2 (SD 19.0) months at the first test, 65.9 (SD 20.5 months) at the second test and 74.9 (SD 20.2) months at the third test.

\section{Statistical analysis}

Single descriptive statistics (i.e. means, SDs and ranges) and subgroup comparisons were performed. Mean values for subgroups were compared using Student's two-tailed $t$-test or the Wilcoxon test for related groups, as appropriate. Non-parametric statistics were usually selected, because the number of subjects in the groups was relatively small and the results did not follow a normal distribution. Statistical significance was defined as $p<0.05$. Unfortunately, the number of children in several subgroups was not large enough to enable statistically significant conclusions. Correlations were calculated using Spearman's rho coefficient or the Pearson productmoment coefficient, in order to determine the strength of relationships between children's test scores and other characteristics. Multiple regression analysis was performed in order to identify which factors accounted for the variance in individuals' vocabulary outcomes.

\section{Results}

At the first test, the entire study group scored below the normative population (on average) on the standardised receptive vocabulary tests (T-score 38.1; SD 15.0). The average increase seen at the second test was poor, but rose over time, indicating a rate of improvement to the lower age-appropriate range of hearing children (Table III). The mean lexical test outcome score at the third test was 42.4 (SD 15.7), which was significantly different from the first test score $(p=0.02)$. Children growing up bilingually demonstrated statistically significantly lower receptive vocabulary scores, on average, compared with children growing up monolingually (at test one, $p=$ 0.025 ; at test two, $p=0.038$; at test three, $p=$ $0.028)$. It was not possible to monitor the effects of the second oral language.

Generally, children not receiving any therapy (i.e. those whose receptive vocabulary size at test one was age-appropriate or better) had a significantly larger mean receptive vocabulary at test three (49.1; SD 
TABLE III

SUBJECTS' MEAN RECEPTIVE VOCABULARY T-SCORES* AT THE THREE TEST POINTS

\begin{tabular}{|c|c|c|c|c|c|c|c|}
\hline \multirow[t]{2}{*}{ Subgroup } & \multirow[t]{2}{*}{ Test point } & \multicolumn{2}{|c|}{ All } & \multicolumn{2}{|c|}{ Monolingual } & \multicolumn{2}{|c|}{ Bilingual } \\
\hline & & $\mathrm{M}(\mathrm{SD})$ & $n$ & $\mathrm{M}(\mathrm{SD})$ & $n$ & $\mathrm{M}(\mathrm{SD})$ & $n$ \\
\hline \multicolumn{8}{|l|}{ Degree of hearing loss } \\
\hline \multirow[t]{3}{*}{ Mild ( $>20-40 \mathrm{~dB}$ HL) } & $\mathrm{t} 1$ & $48.8(13.7)^{\dagger}$ & 10 & $51.9(11.6)^{\dagger}$ & 8 & 36.5 (19.1) & 2 \\
\hline & $\mathrm{t} 2$ & $50.8(10.5)$ & 10 & $53.8(7.1)$ & 8 & $39.0(17.0)$ & 2 \\
\hline & $\mathrm{t} 3$ & $57.7(3.3)^{\dagger}$ & 10 & $57.8(3.3)^{\dagger}$ & 8 & $57.5(4.9)$ & 2 \\
\hline \multirow{3}{*}{ Moderate (41-70 dB HL) } & $\mathrm{t} 1$ & $36.2(14.3)^{\dagger}$ & 17 & $40.8(14.5)$ & 12 & $25.2(4.9)$ & 5 \\
\hline & $\mathrm{t} 2$ & $38.1(11.9)$ & 17 & $41.9(12.1)$ & 12 & $28.8(3.3)$ & 5 \\
\hline & $\mathrm{t} 3$ & $39.6(14.4)^{\dagger}$ & 17 & $43.7(15.1)$ & 12 & $29.8(5.5)$ & 5 \\
\hline \multirow[t]{3}{*}{ Severe (71-90 dB HL) } & $\mathrm{t} 1$ & $24.8(3.5)$ & 4 & $23.0(-)$ & 2 & $26.5(4.9)$ & 2 \\
\hline & $\mathrm{t} 2$ & $25.8(5.5)$ & 4 & $23.0(-)$ & 2 & $28.5(7.8)$ & 2 \\
\hline & $\mathrm{t} 3$ & $26.8(5.7)$ & 4 & $29.0(8.5)$ & 2 & $24.5(2.1)$ & 2 \\
\hline \multirow{3}{*}{ Profound ( $>90$ dB HL) } & $\mathrm{t} 1$ & $28.0(7.1)$ & 2 & $23.0(-)$ & 1 & $33.0(-)$ & 1 \\
\hline & $\mathrm{t} 2$ & $27.0(5.7)$ & 2 & $23.0(-)$ & 1 & $31.0(-)$ & 1 \\
\hline & $\mathrm{t} 3$ & $21.5(2.1)$ & 2 & $23.0(-)$ & 1 & $20.0(-)$ & 1 \\
\hline \multicolumn{8}{|l|}{ Age at diagnosis } \\
\hline \multirow[t]{3}{*}{$\leq 53 \mathrm{mths}$} & $\mathrm{t} 1$ & $33.9(15.2)^{\dagger}$ & 16 & $36.5(15.8)^{\dagger}$ & 13 & $23(-)$ & 3 \\
\hline & $\mathrm{t} 2$ & $36.4(14.8)$ & 16 & $39.2(15.1)$ & 13 & $24.3(2.3)$ & 3 \\
\hline & $\mathrm{t} 3$ & $41.3(16.8)^{\dagger}$ & 16 & $43.1(16.8)^{\dagger}$ & 13 & $33.3(17.9)$ & 3 \\
\hline \multirow[t]{3}{*}{$>53 \mathrm{mths}$} & $\mathrm{t} 1$ & $42.1(14.1)$ & 17 & 49.9 (11.1) & 10 & $30.9(9.7)$ & 7 \\
\hline & $\mathrm{t} 2$ & $42.9(11.5)$ & 17 & $49.2(9.4)$ & 10 & $33.9(7.7)$ & 7 \\
\hline & $\mathrm{t} 3$ & $43.5(14.9)$ & 17 & 50.7 (11.7) & 10 & $33.3(13.4)$ & 7 \\
\hline \multirow[t]{4}{*}{ All } & & & & & & & \\
\hline & $\mathrm{t} 1$ & $38.1(15.0)^{\dagger}$ & 33 & $42.3(15.3)^{\dagger}$ & 23 & $28.5(8.8)$ & 10 \\
\hline & $\mathrm{t} 2$ & $39.8(13.4)$ & 33 & $43.6(13.6)$ & 23 & $31.0(7.9)$ & 10 \\
\hline & $\mathrm{t} 3$ & $42.4(15.7)^{\dagger}$ & 33 & $46.4(15.0)^{\dagger}$ & 23 & $33.3(13.8)$ & 10 \\
\hline
\end{tabular}

*Compared with normative populations (T-score: mean $(\mathrm{M})=50$, standard deviation $(\mathrm{SD})=10)$. ${ }^{\dagger}$ Statistically significant difference between the means: $p<0.05 . \mathrm{t}=$ test; mths $=$ months

15.0), compared with those receiving oral speech-language therapy for varying periods of time (39.5; SD 15.1). There was no association between the duration of speech-language therapy and children's vocabulary scores. Treatment duration tended to increase slightly with increases in hearing loss severity (0.25; not significant; see Table IV).

Analyses were also performed for subgroups classified by degree of hearing loss and age at diagnosis, subdivided into monolingual and bilingual children (see Table III).

\section{Degree of hearing impairment}

Children with mild hearing loss exhibited a mean vocabulary $\mathrm{T}$-score in the lower average range at test one (48.8), which increased significantly over time (to 57.7). At test one, the majority of these children performed in the normal range, but only two of 10 children had a relatively early diagnosis age (one child at 24 months, another at 28 months).

Children with moderate hearing loss showed a poor mean lexical size (36.2; more than one SD below normal for the tests) at test one. However, this significantly improved, and nearly reached the lower normal population range, at test three (39.6).

Severely hearing-impaired children showed a considerably delayed mean receptive vocabulary performance at test one $(24.8 ; 2.5$ SD below normal for the tests). These children's mean results progressed very slowly (as a result of changes in one child's lexical size), and remained far below the normal range at test three (26.8).

Profoundly hearing-impaired children had a very definite handicap in their receptive vocabulary, independent of the age at which their hearing loss was diagnosed. Their mean result decreased, from 28.0 at test one to 21.5 at test three.

\section{Age at diagnosis}

When children diagnosed with hearing loss at less than 53 months were compared with their later-diagnosed peers (i.e. $>53$ months), it was found that both groups generally achieved higher T-scores at test three. (An age of 53 months was used to enable a split-half comparison of the total group, because of the wide range of ages at diagnosis.) The mean $\mathrm{T}$ score improvement rate was neither as great nor as significant for late-diagnosed subjects, compared with earlier-diagnosed subjects; at test one, the laterdiagnosed children demonstrated a mean receptive vocabulary size in the lower normal range.

Correlations between measures are presented in Table IV. Generally, the degree of hearing loss was significantly negatively correlated to receptive vocabulary development $(r=-0.51$ at test one; $r=$ -0.61 at test two; $r=-0.74$ at test three). In other words, with increasing severity of the disorder, the developmental growth of the receptive lexicon reduced, and this relation became more marked as follow-up time increased. This relationship applied only to children growing up in a monolingual environment. In the 10 bilingual children, no significant correlation was found between degree of hearing loss and receptive vocabulary at tests one and two; however, a strong and significant correlation was found at test three $(r=-0.87)$.

Severity of hearing impairment and age at diagnosis were not significantly correlated $(r=-0.06)$. Age 
TABLE IV

CORRELATION BETWEEN SUBJECTS ${ }^{*}$ RESULTS

\begin{tabular}{|c|c|c|c|c|c|c|c|}
\hline \multirow[t]{2}{*}{ Parameter } & \multirow[t]{2}{*}{ Test } & \multirow[t]{2}{*}{ Age at diagnosis } & \multirow[t]{2}{*}{ Nonverbal intelligence $^{\dagger}$} & \multirow[t]{2}{*}{ Therapy duration } & \multicolumn{3}{|c|}{ Receptive vocabulary } \\
\hline & & & & & $\mathrm{t} 1$ & $\mathrm{t} 2$ & $\mathrm{t} 3$ \\
\hline \multirow[t]{2}{*}{ Hearing loss degree } & $\rho$ & -0.06 & -0.17 & 0.25 & -0.51 & -0.61 & -0.74 \\
\hline & $p$ & 0.75 & 0.36 & 0.16 & 0.0026 & 0.0002 & $<0.0001$ \\
\hline \multirow{2}{*}{ Age at diagnosis } & $r$ & & -0.40 & -0.17 & 0.42 & 0.35 & 0.14 \\
\hline & $p$ & & 0.0241 & 0.52 & 0.0148 & 0.0471 & 0.4520 \\
\hline \multirow[t]{2}{*}{ Nonverbal intelligence $^{\dagger}$} & $r$ & & & 0.18 & 0.27 & 0.30 & 0.38 \\
\hline & $p$ & & & 0.34 & 0.14 & 0.10 & 0.0368 \\
\hline \multirow[t]{2}{*}{ Therapy duration } & $r$ & & & & -0.04 & -0.04 & 0.05 \\
\hline & $p$ & & & & 0.84 & 0.83 & 0.79 \\
\hline \multicolumn{8}{|l|}{ Receptive vocabulary } \\
\hline \multirow[t]{2}{*}{$\mathrm{t} 1$} & $r$ & & & & & 0.93 & 0.78 \\
\hline & $p$ & & & & & $<0.0001$ & $<0.0001$ \\
\hline \multirow[t]{2}{*}{$\mathrm{t} 2$} & $r$ & & & & & & 0.86 \\
\hline & $p$ & & & & & & $<0.0001$ \\
\hline
\end{tabular}

${ }^{*} n=33 ;{ }^{\dagger} n=31 . \mathrm{t}=$ test

at diagnosis was significantly statistically associated with vocabulary size at test one $(r=0.42 ; p=$ $0.0148)$ and test two $(r=0.35 ; p=0.0471)$; thereafter, the size of the correlation decreased (at test three, $r=0.14$; not significant).

The nonverbal intelligence test results of all studied children improved over time, and were significantly related to their receptive vocabulary size at test three $(r=0.38 ; p=0.0368)$.

\section{Prediction of receptive vocabulary development}

Several variables seem to affect the vocabulary development of children with impaired hearing. Multiple regression analysis determined the amount of variance in receptive (aural) vocabulary. Of the four independent variables, three significantly contributed to the variance in receptive vocabulary development: degree of hearing loss $(t=5.43 ; p \leq$ $0.0001)$; age at diagnosis of hearing loss $(t=$ $2.29 ; p=0.03)$; and nonverbal intelligence $(t=2.82$; $p=0.009)$. The fourth independent variable, duration of speech-language therapy (in months) and/or early intervention at home by a specialist teacher of hard-of-hearing children, did not significantly affect variance in receptive vocabulary development $(t=0.94 ; p=0.36)$. Altogether, these variables accounted for 59 per cent of the variance observed.

\section{Discussion}

This study addressed the developmental assessment of receptive (aural) vocabulary outcomes in hearing-impaired children, within an average follow-up period of 18.7 months, using three test points. For the total study group, the average vocabulary increase was minimal between the first and second tests, but then improved between the second and third tests; the group appeared to start off slowly but then speed up. Thus, the difference in results between test one and test three was significant. Blamey et $a .^{29}$ have also demonstrated that hearing impairment slows the rate of receptive vocabulary development; they found very little difference between children with cochlear implants and those with severe hearing loss who used hearing aids. Pittman et $a l .{ }^{30}$ found that the receptive vocabulary test results of 37 children (aged five to 14 years) with moderate sensorineural hearing loss were consistently poorer than those of 60 normal-hearing children, across the age range tested. This retardation in vocabulary development was linked to rapid word-learning skills, investigated in a word-learning experiment.

The majority of children (11 of 13) growing up monolingual with a hearing loss of $<50 \mathrm{~dB}$ had normal test results at test one. Nevertheless, moderate hearing loss may still have had a retarding influence on receptive vocabulary development, especially in conjunction with a bilingual environment and lack of speech-language therapy. Davis et $a .^{31}$ and Gilbertson and Kamhi ${ }^{32}$ found that even mild hearing loss negatively affected receptive vocabulary development. The present study's findings are consistent with those of Yoshinaga-Itano and colleagues, ${ }^{33,34}$ who reported that vocabulary scores worsened with increasing severity of hearing loss. Cochlear implantation may facilitate the acquisition of receptive vocabulary in children with a hearing loss of $>70 \mathrm{~dB}$, according to studies showing a significant increase in vocabulary over time. 16,20,21

Furthermore, analysis of the present data revealed that earlier diagnosis of hearing loss and provision of hearing aids, supplemented with suitable training (which stimulates speech recognition), may have a beneficial effect on aural receptive lexical development. In the present study, no infant had been diagnosed below the age of one year. The earliest diagnoses were at a chronological age of 22 and 24 months, in a moderate hearing-impaired child (without significant lexical improvement) and a mildly impaired one (with increasing vocabulary), respectively. In the present study, the average age of hearing loss diagnosis was extremely late and very far from adequate, because of the lack of mandatory universal newborn hearing screening in Germany (such screening was only implemented in mid-2006 at the University Hospital Goettingen). The results of the present study may help demonstrate the negative effects such a lack of screening 
can have on receptive language development. Kennedy et al. $^{35}$ showed that early detection of bilateral, permanent childhood hearing impairment $(\geq 40 \mathrm{~dB}$ ) was associated with higher scores for receptive language, including vocabulary.

Mildly or moderately hearing-impaired children younger than 53 months of age (using this age as a cut-off to enable split-half comparison of the study group) received greater benefit from hearing aid fitting; they benefited not only due to their lower degree of hearing loss but also as they were better able to utilise the critical cerebral period for language development. However, the finding that children diagnosed at 53 months or older performed better in receptive vocabulary may be biased. Fortyseven per cent of these children (eight of 17) had mild hearing losses, compared with 12 per cent (two of 16) of children diagnosed before the age of 53 months. The earliest diagnosed subjects, with a severe and a profound loss, did not progress lexically, as their hearing aids were unsuccessful in improving their hearing sufficient to allow aural receptive vocabulary development. These two children should in future be assessed to determine whether they meet the (other) pre-conditions for cochlear implantation; they will eventually achieve a better vocabulary development with an implant than with hearing aids.

Early detection and therapy of infant hearing loss seem to have an overall effect on speech and language outcomes. ${ }^{36}$ In the present study, the developmental outcome for mildly to moderately hearing impaired children not receiving oral therapy was in general consistently satisfying. Only two children with mild hearing loss needed oral speech-language therapy. However, a few immigrant children received no oral speech-language therapy at test one, in spite of their diagnosed indication, because their family residential rights had not yet been clarified. However, there may be many complex reasons (e.g. socioeconomic, social, emotional, environmental including parental or family involvement and educational) why these children performed more poorly. Vocabulary status in infancy and childhood is highly related to the child's language learning environment (among other factors). ${ }^{37}$

- The developmental acquisition of receptive vocabulary depends on an interplay between children's aural language input and their cognitive skills

- Investigators generally agree that the receptive (aural) vocabulary size of hearing-impaired children is inferior to that of hearing children; this study confirms this in a German population

- Study findings concur with international research results demonstrating the relationship between hearing-impaired children's receptive vocabulary and their severity of hearing impairment, and also their age of hearing impairment diagnosis
Duration of speech-language therapy did not correlate with receptive vocabulary performance at any time point. Unfortunately, the duration of external treatment by different therapists could not be controlled, and information about the quality of treatment was not available. Perhaps therapy is required over a longer period in children with greater hearing losses before changes in vocabulary become apparent. However, comparison data from a longitudinal study had previously not been available in Germany for the receptive word measure used in this study. The present study is the first to address the development of receptive vocabulary of infants and children with hearing loss.

\section{Conclusion}

In summary, the present findings suggest that development of a receptive vocabulary within the normal (hearing) range is possible if the childhood permanent hearing impairment is mild and/or if it is detected early, if the child grows up monolingual, and if he or she receives oral speech-language intervention (in cases in which current vocabulary is not age-appropriate). Receptive vocabulary outcomes were also influenced by individual differences in underlying cognitive functions. Cognitive skills play an essential role in the vocabulary development of hearing children. ${ }^{38}$ Thus, it is possible that some children in the present study had a specific deficit in phonological memory, which is closely associated with receptive vocabulary development. This problem seems to be independent of hearing impairment. Dawson et $a .^{21}$ found a significant relationship between nonverbal intelligence and receptive language scores (as did the present study) also in young children 5 to 11 years old, using cochlear implants solely, but in children with normal hearing too. So the performance seems to be similar between aided children (as in the present study), children using cochlear implants, and children with normal hearing.

The present study group was based on a regional clinical dataset which contained prospective information (i.e. archive-based data collection). Therefore, findings can be generalised to only a limited degree, partly because of the small number of subjects within the single hearing loss category. Nevertheless, the present study confirms international study results indicating that age-typical receptive (aural) vocabulary development depends on the degree of hearing loss and the age of diagnosis, but also on children's cognitive abilities to learn from their linguistic input. Mayne et al. studied deaf and hard-of-hearing infants and toddlers and found no significant associations between receptive vocabulary size and diagnosis of hearing loss. ${ }^{11}$ However, an association was found between cognitive task performance and receptive vocabulary.

Much more research is required, because there is a difference between receptive vocabulary tested in an artificial situation and the comprehension of spoken words in a normal setting, especially with the additional noise of a kindergarten or school. In 
addition, further research should focus on the separation of the two bilingually hearing-impaired groups (i.e. speech-only environment versus speech plus signing environment). Moreover, phonological memory should be assessed by a spoken digit span task and by non-word repetition. Finally, it is necessary in all German states to conduct prospective investigation of an entire birth cohort, via a systematic infant screening programme (with a high coverage rate), including long-term studies with longer extension. It is time for Germany to move beyond the recommendation stage, regarding universal newborn hearing screening; this may be particularly useful for babies with moderate or severe, permanent childhood hearing impairment. ${ }^{39}$

Nevertheless, the efficacy of universal newborn hearing screening to improve long-term language outcomes remains uncertain, ${ }^{40}$ because only preliminary evidence exists for improved language outcomes. For example, universal newborn hearing screening has been positively related to speech and language performance in children with bilateral hearing loss undergoing early intervention programmes, in a US developmental study of children aged zero to six years. ${ }^{41}$ However, Kennedy and McCann ${ }^{42}$ note that studies from the newborn hearing screening project in question '... are open to a number of criticisms and were rated as 'poor quality' in the systematic review' of Thompson et $a l .{ }^{40}$ The above-mentioned British study by Kennedy et $a .^{35}$ has demonstrated that early detection of childhood hearing loss is associated with higher mid-childhood scores for language but not for speech.

\section{Acknowledgements}

The author gratefully acknowledges the financial support supplied by a grant from the Annelie-Frohn Stiftung. The author also thanks Silke Ohlwein, psychologist, for her assistance in collecting the data and preparing the paper.

\section{References}

1 Benedict H. Early lexical development: comprehension and production. $J$ Child Lang 1979;6:183-200

2 Gupta P, MacWhinney B. Vocabulary acquisition and verbal short term memory: computation and neural bases. Brain Lang 1997;59:267-333

3 Golinkoff RM, Hirsh-Pasek K. Word learning. Icon, index, or symbol? In: Golinkoff RM, Hirsh-Pasek K, Bloom L, Smith LB, Woodward AL, Akhtar N, Tomasello M, Hollich G, eds. Becoming a Word Learner. A Debate on Lexical Acquisition. Oxford: Oxford University Press, 2000;3-15

4 Bates E, Dale PS, Thal D. Individual differences and their implications for theories of language development. In: Fletcher P, MacWhinney B, eds. The Handbook of Child Language. Cambridge: Basil Blackwell, 1995;96-152

5 Marchman V, Bates E. Continuity in lexical and morphological development: a test of the critical mass hypothesis. $J$ Child Lang 1994;21:339-66

6 Thal DJ, Bates E, Zappia MJ, Oroz M. Ties between lexical and grammatical development: evidence from earlytalkers. J Child Lang 1996;23:349-68

7 Bishop DVM, Snowling MJ. Developmental dyslexia and specific language impairment: same or different? Psychol Bull 2004;130:858-86
8 Vermeer A. Breadth and depth of vocabulary in relation to L1/L2 acquisition and frequency of input. Applied Psycholinguistics 2001;22:217-34

9 Moeller MP, Osberger MJ, Eccarius M. Receptive language skills. Monographs of the ASHA 1986;23:41-53

10 Ramkalawan TW, Davis AC. The effects of hearing loss and age of intervention on some language metrics in young hearing-impaired children. Br J Audiol 1992;26: 97-107

11 Mayne A, Yoshinaga-Itano C, Sedey AL. Receptive vocabulary development of infants and toddlers who are deaf or hard of hearing. Volta Rev 2000;100:29-52

12 Lederberg AR, Spencer PE. Vocabulary development of deaf and hard of hearing children. In: Clark MD, Marschak M, Karchmer M, eds. Context, Cognition, and Deafness. Washinton DC: Gallaudet University Press, 2001;88-112

13 Kiese-Himmel C, Ohlwein S. Vocubulary of young children with sensorineural deafness. [in German]. HNO 2002;50:48-54

14 Boothroyd A, Geers AE, Moog JS. Practical implications of cochlear implants in children. Ear Hear 1991; 12(suppl 4):81S-89S

15 Kirk KI, Pisoni DB, Osberger MJ. Lexical effects of spoken word recognition by pediatric cochlear implant users. Ear Hear 1995;16:470-81

16 Robbins AM, Svirsky M, Kirk KI. Children with implants can speak, but can they communicate? Otolaryngol Head Neck Surg 1997;117:155-60

17 Szagun G. Some aspects of language development in normal-hearing children and children with cochlear implants. Am J Otol 1997;18:131-4

18 Szagun G. Language acquisition in children with cochlear implants; First results of a development psycholinguistic study [in German]. Sprache Stimme Gehör 1998;22:133-8

19 Svirsky MA, Robbins AM, Kirk KI, Pisoni DB, Miyamoto RT. Language development in profoundly deaf children with cochlear implants. Psychol Science 2000;11: 153-8

20 El-Hakim H, Levasseur J, Papsin BC, Panesar J, Mount RJ, Stevens D et al. Assessment of vocabulary development in children after cochlear implantation. Arch Otolaryngol Head Neck Surg 2001;127:1053-9

21 Dawson PW, Busby PA, McKay CM, Clark GM. Shortterm auditory memory in children using cochlear-implants and its relevance to receptive language. $J$ Speech Lang Hear Res 2002;45:789-801

22 O'Leary Kane M, Schopmeyer B, Mellon NK, Wang NY, Niparko JK. Prelinguistic communication and subsequent language acquisition in children with cochlear implants. Arch Otolaryngol Head Neck Surg 2004;130:619-23

23 Burgemeister B, Blum LM, Lorge I. Columbia Mental Maturity Scale, 3rd edn. New York: Harcourt Brace Jovanovich, 1972

24 Eggert D. The Columbia Mental Maturity Scale as an individually administered instrument for normally developed children from 3 to 10 years old [in German]. In: Eggert D, ed. Zur Diagnose der Minderbegabung. Beltz: Weinheim, 1992;185-201

25 Becker P, Schaller S, Schmidtke A. Coloured Progressive Matrices. Manual of the German version. Weinheim: Beltz, 1980

26 Grimm H. Language Development Test for Two Years Old [in German]. Göttingen: Hogrefe, 2000

27 Dunn LM, Dunn LM. Peabody Picture Vocabulary Test Revised. Circle Pines, Minnesota: American Guidance Service, 1981

28 Hebbel G, Horn R. French Pictorial Test of Intelligence [in German]. Weinheim: Beltz, 1976

29 Blamey PJ, Sarant JZ, Paatsch LE, Barry JG, Bow CP, Wales RJ et al. Relationships among speech perception, production, language, hearing loss, and age in children with impaired hearing. J Speech Lang Hear Res 2001;44: 264-85

30 Pittman AL, Lewis DE, Hoover BM, Stelmachowicz PG. Rapid word-learning in normal hearing and hearing-impaired children: effects of age, receptive vocabulary, and high-frequency amplification. Ear Hear 2005; 6:619-29 
31 Davis JM, Elfenbein J, Schum R, Bentler RA. Effects of mild and moderate hearing impairments on language, educational, and psychosocial behavior of children. J Speech Hear Disord 1986;51:53-62

32 Gilbertson M, Kamhi A. Novel word learning in children with hearing impairment. J Speech Hear Res 1995;38: $630-42$

33 Yoshinaga-Itano C, Sedey AL, Coulter DK, Mehl AL. Language of early- and later-identified children with hearing loss. Pediatrics 1998;102:1161-71

34 Yoshinaga-Itano C. Early identification: an opportunity and challenge for audiology. Semin Hear 1999;20:317-31

35 Kennedy CR, McCann DC, Campbell MJ, Law CM, Mullee M, Petrou S et al. Language ability after early detection of permanent childhood hearing impairment. $N$ Engl J Med 2006;354:2131-41

36 Neumann K, Gross M, Böttcher P, Euler HA, SpormannLagodzinski M, Polzer M. Effectiveness and efficiency of a universal newborn hearing screening in Germany. Folia Phoniatr Logop 2006;58:440-55

37 Huttenlocher J. Language input and language growth. Prev Med 1998:27:195-9

38 Dromi E. Early lexical development. In: Barrett M, ed. The Development of Language: Studies in Development Psychology. Philadelphia: Psychology Press, 1999;99-131

39 Kennedy CR. Controlled trial of universal neonatal screening for early identification of permanent childhood hearing impairment: coverage, positive predictive value, effect on mothers and incremental yield. Wessex Universal Neonatal Screening Trial Group. Acta Paediatr Suppl 1999;88:73-5

40 Thompson DC, McPhillips H, Davis RL, Lieu TL, Homer $\mathrm{CJ}$, Helfand M. Universal newborn hearing screening: summary of evidence. JAMA 2001;286:2000-10

41 Yoshinaga-Itano C, Coulter D, Thompson V. The Colorado Newborn Hearing Screening Project: effects on speech and language development for children with hearing loss. J Perinatol 2000;20:S132-7

42 Kennedy C, McCann D. Universal neonatal hearing screening moving from evidence to practice. Arch Dis Child Fetal Neonatal Ed 2004;89:F378-83

\section{Appendix 1. The Goettinger Hearing Language Register}

The Goettinger Hearing Language Register comprised a consecutive series of children aged up to
10 years and diagnosed as having permanent, peripheral hearing loss requiring amplification, from 1 October 1994 to 30 September 2004 (i.e. a total of 286 children with sensorineural hearing loss: 217 bilateral, 69 unilateral). The children came to the out-patient clinic of the Department of Phoniatrics/ Pedaudiology at the University of Goettingen, which provided diagnostic and habilitation services, because of parental self-referral or referral by paediatricians, otolaryngologists or general practitioners. All children received a prescription for acoustic hearing aids, based on individual audiometric information. Their data were stored in a database (ethical approval was obtained). The data included severity of hearing loss, socio-demographic variables and results of performance tests (especially for language skills). Children were involved in regular longitudinal, psychological monitoring of their developmental status and were psychologically evaluated by a certified clinical psychologist. A battery of standardised tests was administered in the clinic every six to 10 months after the hearing aid was fitted, in order to monitor developmental progress.

Address correspondence to:

Professor Dr rer nat Dipl-Psych Christiane Kiese-Himmel, Clinical Psychologist,

Department of Phoniatrics/Pedaudiology,

Georg-August-University Goettingen,

Robert Koch Str 40

D-37075 Goettingen, Germany.

Fax: 0049 551/392812

E-mail: ckiese@med.uni-goettingen.de

Dr C Kiese-Himmel takes responsibility for the integrity of the content of the paper.

Competing interests: None declared 
Reproduced with permission of the copyright owner. Further reproduction prohibited without permission. 